\title{
Acute Consumption of Bordo Grape Juice and Wine Improves Serum Antioxidant Status in Healthy Individuals and Inhibits Reactive Oxygen Species Production in Human Neuron-Like Cells
}

\author{
Cristiane Copetti $\mathbb{D D}^{1},{ }^{1}$ Fernanda Wouters Franco $\left(\mathbb{D},{ }^{1}\right.$ Eduarda da Rosa Machado $\left(\mathrm{D},{ }^{1}\right.$ \\ Marcela Bromberger Soquetta, ${ }^{2}$ Andréia Quatrin $\left(\mathbb{D},{ }^{1}\right.$ Vitor de Miranda Ramos $\left(\mathbb{D},{ }^{3}\right.$ \\ José Cláudio Fonseca Moreira, ${ }^{3}$ Tatiana Emanuelli ${ }^{1},{ }^{1}$ Cláudia Kaehler Sautter, ${ }^{1}$ \\ and Neidi Garcia Penna $\left.{ }^{1}\right)^{1}$ \\ ${ }^{1}$ Department of Food Technology and Science, Center of Rural Sciences, Federal University of Santa Maria (UFSM), \\ 1000 Roraima Avenue, 97105-900 Santa Maria, RS, Brazil \\ ${ }^{2}$ Department of Chemical Engineering, Center of Technology, Federal University of Santa Maria (UFSM), 1000 Roraima Avenue, \\ 97105-900 Santa Maria, RS, Brazil \\ ${ }^{3}$ Department of Biochemistry, Center of Oxidative Stress Research (CEEO), Federal University of Rio Grande do Sul (UFRGS), \\ 2600 Ramiro Barcelos Street-Annex, 90035-003 Porto Alegre, RS, Brazil
}

Correspondence should be addressed to Cristiane Copetti; copetti.cris@gmail.com

Received 4 September 2017; Accepted 30 November 2017; Published 1 March 2018

Academic Editor: Michael B. Zemel

Copyright (c) 2018 Cristiane Copetti et al. This is an open access article distributed under the Creative Commons Attribution License, which permits unrestricted use, distribution, and reproduction in any medium, provided the original work is properly cited.

\begin{abstract}
Few studies investigated the biological effects of American grape cultivars. We investigated the metabolic response after acute consumption of grape juice or wine from Bordo grapes (Vitis labrusca) in a placebo-controlled crossover study with fifteen healthy volunteers. Blood samples were collected 1 hour after the intake of $100 \mathrm{~mL}$ of water, juice, or wine to measure TBARS, ABTS, FRAP, glucose, and uric acid levels. To evaluate differences in cellular response, intracellular reactive species production (DCFH-DA) and metabolic mitochondrial viability (MTT) were assessed after exposure of human neuron-like cells (SH-SY5Y) to juice or wine. Glycemia was reduced after juice or wine consumption, whereas blood levels of uric acid were reduced after juice consumption but increased after wine consumption. Juice and wine consumption reduced plasma lipid peroxidation and increased plasma antioxidant capacity (ABTS and FRAP assays). Furthermore, juice inhibited $\mathrm{H}_{2} \mathrm{O}_{2}$-induced intracellular production of reactive species (RS) and increased the viability of SH-SY5Y cells. In contrast, wine (dealcoholized) exhibited a per se effect by inducing the production of RS and reducing cell viability. These results indicate a positive impact of acute consumption of Bordo juice and wine on human oxidative status, whereas only juice had protective effects against oxidative stress-induced cytotoxicity.
\end{abstract}

\section{Introduction}

Oxidative stress is caused by the insufficient capacity of biological systems to neutralize the excessive production of reactive species [1], which leads to oxidative damage in cells. Neuronal cells are particularly susceptible to reactive oxygen species (ROS) and reactive nitrogen species (RNS) due to their high metabolic activity, low antioxidant capacity, and their nonreplicative nature. Furthermore, the abundance of mitochondria in brain cells increases the generation of reactive species [2].

Fruits and vegetables have many bioactive compounds such as polyphenols, which have antioxidant properties with a role in the protection of cellular macromolecules against oxidative damage induced by ROS and RNS [3-5]. There is increasing evidence that polyphenols may protect cell constituents against oxidative damage and, therefore, limit the risk of various degenerative diseases associated with 
oxidative stress [6]. Studies have repeatedly shown an inverse association between the risk of several chronic human diseases and the consumption of polyphenol-rich diet [7]. The phenolic group of polyphenols can accept an electron to form relatively stable phenoxyl radicals, thereby disrupting chain oxidative reactions in cellular components. It is well established that polyphenol-rich foods and beverages may increase plasma antioxidant capacity $[8,9]$.

Grapes contain high levels of polyphenols, which have been demonstrated to reduce oxidative stress, inflammatory response, and the oxidation of low density lipoprotein cholesterol (LDL-c), while inhibiting platelet aggregation and improving protection against atherothrombotic episodes. Such actions promote beneficial effects on coronary heart disease (CHD) and atherosclerosis [10-12]. Red wines are rich in polyphenols, such as phenolic acids (gallic acid, caffeic acid, $p$-coumaric acid, and others), stilbenes (transresveratrol), and flavonoids (catechin, epicatechin, quercetin, rutin, myricetin, and others) [13]. Therefore, a regular consumption of red wine has been linked with the "French paradox," which explains the apparent compatibility of a high-fat diet with a low mortality from CHD. Also, current evidence suggests that wine consumption is correlated with a reduction in the incidence of neurodegenerative diseases associated to oxidative stress such as Alzheimer's and Parkinson's disease [14]. Grape juice is a natural and nonalcoholic beverage that contains sugars, minerals, and phenolic compounds like anthocyanins, among which malvidin 3,5-diglucoside is the major one [15]. This beverage has been shown to exert antioxidant activity in vitro and in vivo, as well as hypolipidemic and anti-inflammatory effects in rats and humans [16-18].

However, few studies have compared the effects of wine and juice consumption in biological parameters of humans, and these studies used European grape species (Vitis vinifera) [19-21]. In contrast, the biological effects of wine and juice from American grape species (Vitis labrusca) have not been compared. This investigation is particularly interesting as the red grape cultivar "Bordo" ( V. labrusca), which is the most important grape cultivated in Brazil [15], has been recently demonstrated to exhibit higher content of phenolic compounds and in vitro antioxidant capacity than $V$. vinifera species [22]. In the present study, we compared the biological effects of juice and wine from "Bordo" grapes ( V. labrusca L) by assessing blood antioxidant response after human consumption and the oxidative cellular response in human neuron-like cells (SH-SY5Y).

\section{Materials and Methods}

2.1. Bordo Grape Juice and Wine. The commercial samples of Bordo grape juice and Bordo wine were produced by a winemaker (Casa Perini, Farroupilha, RS, Brazil). The grape fruits used to prepare juice and wine were harvested in Farroupilha $\left(29^{\circ} 13^{\prime} 30^{\prime \prime} \mathrm{S}, 51^{\circ} 20^{\prime} 52^{\prime \prime} \mathrm{W}\right.$, altitude $\left.783 \mathrm{~m}\right)$, in the State of Rio Grande do Sul, Brazil, on January 2014. Bordo grape juice was prepared by the enzymatic method, in which grape is crushed and then heated to at least $65^{\circ} \mathrm{C}$ in a hot macerator. Next, commercial pectolytic enzymes are added and must be kept between $55^{\circ} \mathrm{C}$ and $60^{\circ} \mathrm{C}$ during 1-2 $\mathrm{h}$. The extracted juice is then clarified, pasteurized, and bottled [23]. Bordo wine was obtained from vinification process by the coupled dispositive to the crushing machine that is called dewaxing. In winemaking of red wine, grape skin remains inside tanks during fermentation for extraction of anthocyanin pigments [24].

\subsection{Determination of Bioactive Compounds in Bordo Juice and} Wine. The total phenolic content was determined at $760 \mathrm{~nm}$ using the Folin-Ciocalteu method and gallic acid as standard [25]. Total anthocyanin content was assessed at $520 \mathrm{~nm}$ as the difference of absorbance before and after sample decoloration using sodium bisulfite at $\mathrm{pH} 0.8$ and was expressed as $\mathrm{mg}$ of malvidin-3-glucoside/L [26]. The total flavonoid content was estimated at $510 \mathrm{~nm}$ using a standard curve of catechin (0-200 mg/L) [27].

2.3. Antioxidant Capacity of Bordo Juice and Wine. The antioxidant capacity of grape juice and red wine were determined using the 2,2' -azino-bis (3-ethylbenzothiazoline6-sulphonic acid) (ABTS) and ferric reducing antioxidant power (FRAP) methods as described by Re et al. [28] and Benzie and Strain [29], respectively. The ABTS assay is assessed at $764 \mathrm{~nm}$ and is based on the ability of the sample to scavenge the cation radical $\mathrm{ABTS}^{+}$. The FRAP assay is assessed at $620 \mathrm{~nm}$ and is based on the reduction of ferrictripyridyltriazine (Fe III-TPTZ) by antioxidants present in the samples forming ferrous-tripyridyltriazine (Fe II-TPTZ), a blue-colored product. Trolox was used in the calibration curve.

\subsection{In Vivo Study}

2.4.1. Participants. The study design was approved by the Ethics Committee of Federal University of Santa Maria (CAAE 39197614.3.0000.5346), and all subjects signed a written agreement before participating. Fifteen healthy volunteers, with mean age $24.0 \pm 3.6$, were recruited from the University staff. The health status and medical history of volunteers were examined by a structured interview for inclusion or exclusion according to the criteria shown in Table 1.

2.4.2. Study Design. In this crossover-controlled clinical study, 15 volunteers were included, 10 women $(67 \%)$ and 5 men (33\%). All participants received the three treatments, namely, Bordo grape juice, Bordo wine, and water (control) with a washout period of 1 week between treatments. The sequence of the treatments was randomized among the participants as depicted in Figure 1.

Participants were oriented to follow a low-antioxidant diet for $48 \mathrm{~h}$ prior to the day of intervention, avoiding some fruits, vegetables, and juices, mainly rich in anthocyanins, tea, coffee, cocoa foodstuffs, and alcoholic beverages. This 
TABLE 1: Selection criteria of study participants.

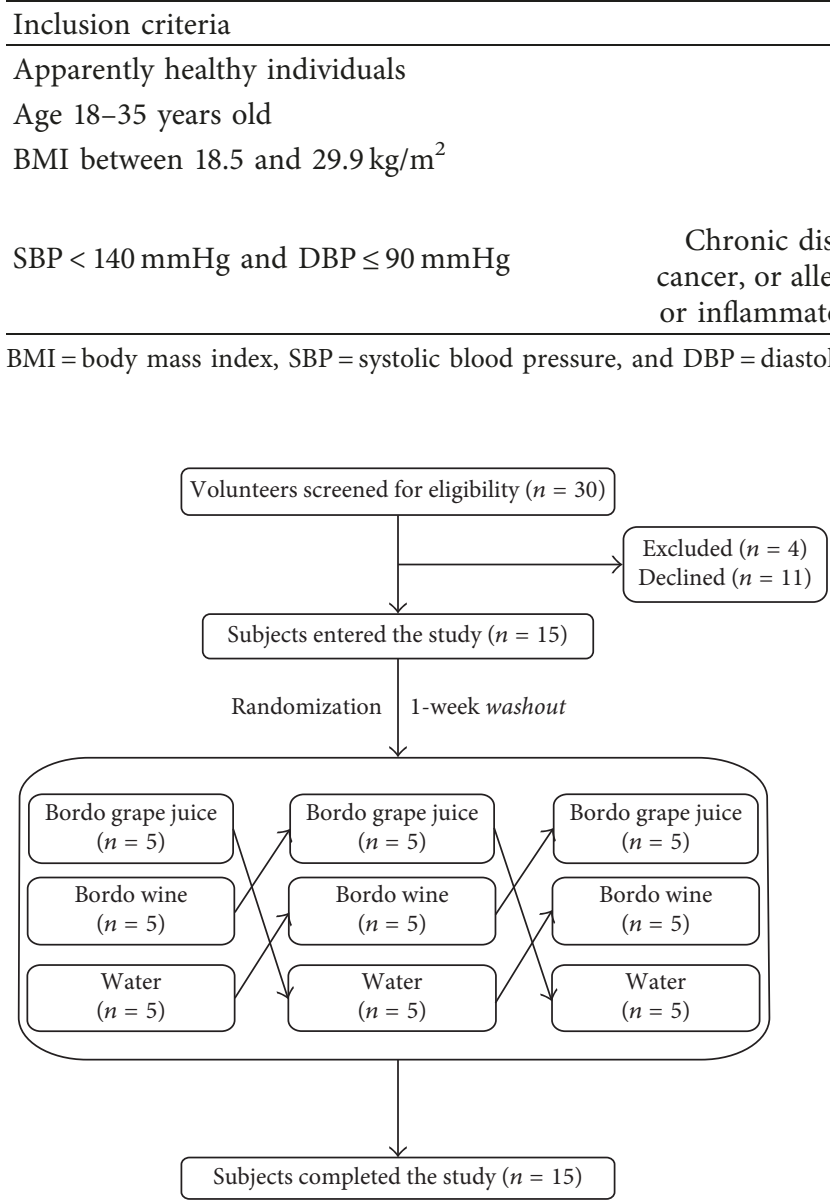

FIgURE 1: Flowchart of the selection of subjects in the controlled intervention study.

dietary restriction was aimed to reduce dietary phenolic compounds from blood as these compounds are typically cleared within $48 \mathrm{~h}$ of consumption [30]. The intake of energy, macronutrients, dietary fiber, and antioxidants before the intervention was monitored using a prospective $48 \mathrm{~h}$ dietary record. Each participant served as his own control because we compared data obtained after either juice, wine, or water consumption with the respective baseline values before consumption. In the day of intervention, baseline blood samples were collected after overnight fasting (12 h), then subjects consumed $100 \mathrm{~mL}$ of Bordo grape juice, Bordo wine, or water. One hour after drinking, test blood samples were collected. This protocol was chosen based on a previous study that revealed maximal antioxidant capacity and phenolic concentration in serum $1 \mathrm{~h}$ after the intake of the fruit or beverage [30]. No food was provided during this period.

2.4.3. Blood Collection and Analyses. Fasting venous blood samples were collected through aseptic venipuncture into heparinized tubes and EDTA-containing tubes that were centrifuged $(1500 \times \mathrm{g}, 10 \mathrm{~min})$ to yield plasma for thiobarbituric acid reactive species (TBARS), ABTS, and FRAP analysis. Blood collected in tubes without additives was centrifuged $(1500 \times \mathrm{g}, 10 \mathrm{~min})$ to yield serum for analysis of uric acid and glucose. Serum and plasma samples were stored at $-80^{\circ} \mathrm{C}$ until analysis.

Uric acid and glucose were determined in serum using commercially available enzymatic kits (Bioclin, Belo Horizonte, Brazil). Lipid peroxidation was determined by measurement of TBARS at $535 \mathrm{~nm}$ in plasma [31]. The antioxidant capacity of plasma was assessed by the ABTS [28] and FRAP assays [29].

2.5. Cell Culture Assays. Human neuron-like cell line SHSY5Y obtained from the European Collection of Authenticated Cell Cultures (ECACC) were maintained in $75 \mathrm{~cm}^{2}$ flasks containing DMEM/F12 medium (1:1) supplemented with $10 \%$ fetal bovine serum (FBS) and $1 \times$ antibiotic/antimycotic solution (Sigma-Aldrich). Cells were cultured in a humidified incubator set at $37^{\circ} \mathrm{C}$ with $5 \% \mathrm{CO}_{2}$. When cultures reached confluence, cells were trypsinized and seeded at a density of $30 \times 10^{3}$ cells $/ \mathrm{cm}^{2}$ in 96 -well culture plates. Treatments started 24 hours after seeding. All treatments were performed using $1 \%$ FBS supplemented medium. Bordo juice and wine were freezedried to remove water and alcohol and then dissolved in culture medium at the desired concentration $(\mathrm{w} / \mathrm{v})$. Cells were exposed to these juice and wine solutions or vehicle (culture medium).

2.5.1. Determination of Intracellular ROS Production. Intracellular ROS production was detected using the $2^{\prime}, 7^{\prime}$ dichlorofluorescein diacetate (DCFH-DA, Sigma) as described [32]. Cells were pretreated with Bordo juice or wine (solutions in culture medium, Section 2.3) or vehicle (culture medium) during $2 \mathrm{~h}$ and then incubated in the absence (control) or presence of $\mathrm{H}_{2} \mathrm{O}_{2}(100 \mu \mathrm{M})$ for $3 \mathrm{~h}$ before monitoring DCF fluorescence. $\mathrm{H}_{2} \mathrm{O}_{2}$ was used as a positive control to induce ROS generation [33]. DCFHDA stock solution was dissolved in DMSO at a final concentration of $10 \mathrm{mM}$ and stored at $-20^{\circ} \mathrm{C}$ protected from light. Before cells were treated, DCFH-DA was diluted to $100 \mu \mathrm{M}$ using $1 \%$ FBS-supplemented medium solution. After addition of DCFH-DA, cells were incubated at $37^{\circ} \mathrm{C}$, with $5 \% \mathrm{CO}_{2}$, and protected from light exposure for $1 \mathrm{~h}$. After DCFH internalization, the medium was replaced by fresh $1 \%$ FBS-supplemented medium solution. When internalized, ROS cause DCFH oxidation, and it becomes a fluorophore (DCF), which was quantified 
TABLE 2: Baseline characteristics of subjects enrolled in the study.

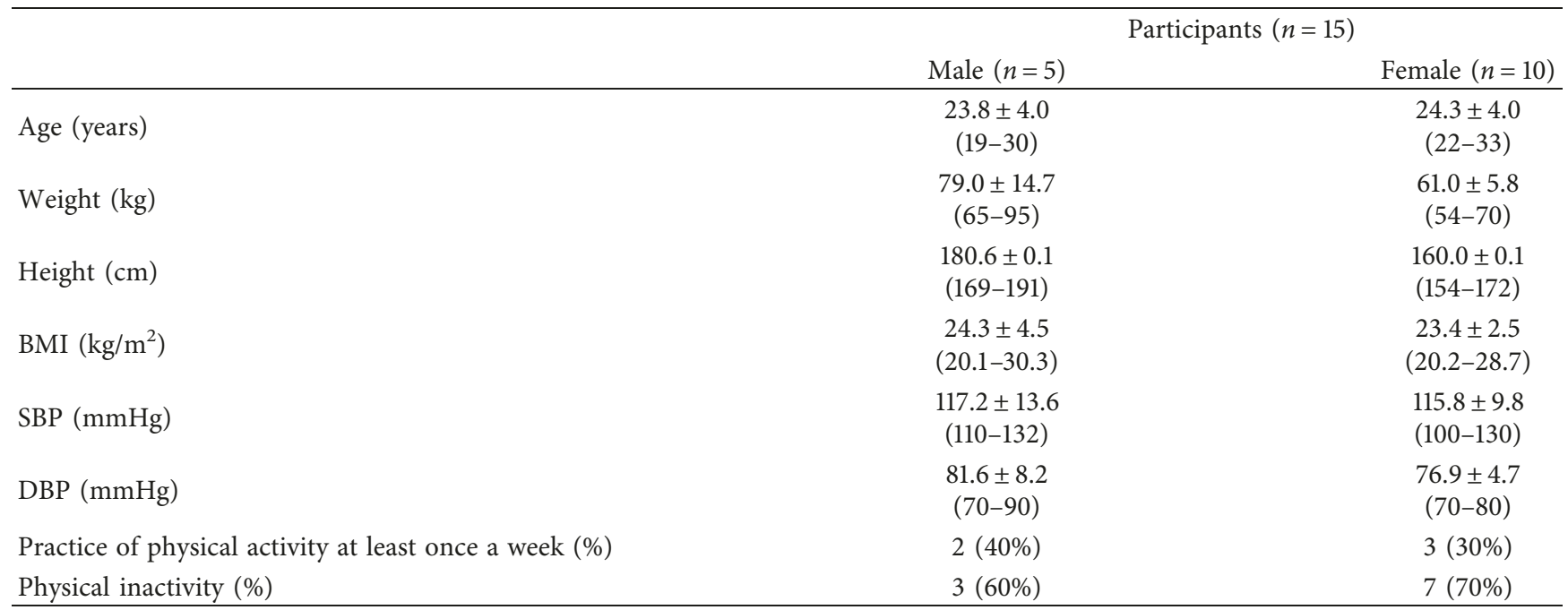

Data are expressed as means \pm SEM (minimum-maximum), except for the physical activity/inactivity that was expressed as the number of participants (\%). $\mathrm{BMI}=$ body mass index, $\mathrm{SBP}=$ systolic blood pressure, and $\mathrm{DBP}=$ diastolic blood pressure .

using a SpectraMAX i3 (Molecular Devices) fluorescence plate reader $(\mathrm{Ex} / \mathrm{Em}=485 / 532 \mathrm{~nm})$. Fluorescence was monitored, and the area under the curve (AUC) of fluorescence versus time was calculated.

2.5.2. Metabolic Mitochondrial Viability. Metabolic mitochondrial viability was assessed by the MTT (3-(4,5dimethylthiazol-2-yl)-2,5-diphenyl tetrazolium bromide) assay as previously described [34]. SH-SY5Y cells were plated onto 96-well plates and exposed to Bordo juice or wine (solutions in culture medium, see Section 2.3) or vehicle (culture medium) during $24 \mathrm{~h}$. Parallel sets of wells were run in the absence or presence of $\mathrm{H}_{2} \mathrm{O}_{2}(100 \mu \mathrm{M})(\mathrm{co}-$ exposure scheme with juice/wine), which was used as a positive control to induce cell death [35]. Then, cells were incubated with MTT for $45 \mathrm{~min}$ at $37^{\circ} \mathrm{C}$ in a humidified $5 \% \mathrm{CO}_{2}$ atmosphere. The medium was then removed, and plates were shaken with DMSO for $30 \mathrm{~min}$. The optical density of each well was measured at $550 \mathrm{~nm}$ (test) and $690 \mathrm{~nm}$.

2.6. Statistical Analysis. All the analyses were performed in triplicate. Results were analyzed using the Statistica software package (StatSoft Inc., Tulsa, Okla, USA) and expressed as mean \pm SEM. The parameters of the juice and wine were compared by the Student's $t$-test. The effects of wine, juice, and water intake on blood parameters were evaluated by the paired $t$-test to compare baseline versus test data (intragroup comparison) and by analyses of variance followed by Tukey's test for intergroup comparison. Significance was set at $p<0.05$.

\section{Results}

3.1. Characteristics of the Subjects. General characteristics of the study group are presented in Table 2 . Fifteen apparently healthy individuals, 5 men and 10 women, respectively, with mean age $24.1 \pm 3.7$ and body mass index of $23.7 \pm 3.2 \mathrm{~kg} / \mathrm{m}^{2}$ were included. The systolic and diastolic blood pressures of participants were within the intervals of optimal and normal blood pressures according to the Brazilian Society of Hypertension, Brazilian Society of Cardiology, and Brazilian Society of Nephrology [36] and according to US-American Hypertension Guideline [37].

\subsection{Bordo Grape Juice and Wine Antioxidant Activity In} Vitro. The chemical composition of Bordo grape juice and wine in the same serving size (portion) administered to healthy individuals in this study is shown in Table 3. Grape juice and wine showed high amounts of total phenolic content, but wine had higher amount than grape juice (Table 3, $p<0.05)$. The concentration of total monomeric anthocyanins and total flavonols was also higher in wine compared with grape juice (Table 3, $p<0.05$ ).

The antioxidant activities were elevated in the two grape beverages used in this study. Bordo wine showed higher antioxidant capacity by the ABTS method, determined by the decolorization of the $\mathrm{ABTS}^{+}$, through measuring the reduction of the radical cation as the percentage inhibition of absorbance at $734 \mathrm{~nm}$, when compared with grape juice (Table 3, $p<0.05)$. On the other hand, the wine antioxidant capacity assessed by the FRAP method, based on the ferric ion reduction $\left(\mathrm{Fe}^{+3}\right)$ capacity, did not differ from juice (Table 3, $p<0.05)$.

3.3. Acute Consumption of Bordo Juice and Wine. After the consumption of Bordo grape juice and wine, serum levels of TBARS were, respectively, decreased by $22.3 \%$ and $25.7 \%$ compared with baseline values $(p<0.001)$, but no significant differences were observed between Bordo juice and wine (Figure 2(a)). Changes in TBARS levels after juice and wine intake were significantly different from changes observed 
TABle 3: Phenolic composition and in vitro antioxidant activity of the Bordo grape juice and wine.

\begin{tabular}{lcr}
\hline Parameter & Bordo juice & Bordo wine \\
\hline Total polyphenol index $(\mu \mathrm{mol}$ GAE $/ 100 \mathrm{~mL})$ & $184.2 \pm 13.1^{\mathrm{b}}$ & $371.3 \pm 9.6^{\mathrm{a}}$ \\
Total anthocyanins $(\mu \mathrm{mol}$ malvidin-3- & $17.5 \pm 22.5^{\mathrm{b}}$ & $66.74 \pm 10.2^{\mathrm{a}}$ \\
glucoside/ $100 \mathrm{~mL})$ & $84.5 \pm 9.7^{\mathrm{b}}$ & $93.6 \pm 4.6^{\mathrm{a}}$ \\
Total flavonols $(\mu \mathrm{mol}$ catechin $/ 100 \mathrm{~mL})$ & & $448.7 \pm 12.1^{\mathrm{a}}$ \\
Total antioxidant activity & $316.5 \pm 14.6^{\mathrm{b}}$ & $234.9 \pm 7.1^{\mathrm{a}}$ \\
$\quad$ ABTS $(\mu \mathrm{mol}$ TEAC/ $100 \mathrm{~mL})$ & $234.6 \pm 9.5^{\mathrm{a}}$ & \\
$\quad$ FRAP $(\mu \mathrm{mol}$ TEAC/ $100 \mathrm{~mL})$ & & \\
\hline
\end{tabular}

Values are means \pm SEM of determinations in triplicate. ${ }^{\text {a,b }}$ Different superscript letters denote significant differences (Tukey's test, $p<0.05$ ). GAE $=$ gallic acid equivalent; TEAC $=$ Trolox equivalent antioxidant capacity.

after water intake $(p<0.05)$, which increased $(13.6 \%)$ TBARS levels compared with baseline values $(p<0.001)$.

A significant increase in the antioxidant capacity levels, measured by ABTS and FRAP assays, was found $1 \mathrm{~h}$ after the consumption of Bordo juice $(9.1 \%$ and $14.1 \%$, resp.) and wine $(7.8 \%$ and $12.5 \%$, resp.), compared with baseline values (Figures 2(b) and 2(c); $p<0.05$ ). Changes in ABTS and FRAP levels after juice and wine intake were significantly $(p<0.05)$ different from changes observed after water intake, which decreased ABTS $(9.7 \% ; p<0.001)$ and FRAP values $(9.8 \% ; p<0.05)$ compared with baseline values.

Significant changes were detected in the mean values of serum glucose and uric acid after the intake of the Bordo grape juice and wine (Table 4). Blood glucose was reduced after consumption of Bordo juice and wine compared with baseline values $(p<0.01)$. Furthermore, wine triggered a greater decrease in blood glucose levels compared with water intake $(-8.8 \%$ versus $-2.0 \%$; $p<0.05)$. Consumption of wine had a different effect in blood uric acid levels compared with water and juice $(p<0.05$; Table 4$)$. Compared with baseline values, blood uric acid levels were increased after the consumption of Bordo grape wine $(p<0.05)$ but decreased after the consumption of water and Bordo grape juice $(p<0.01)$.

3.4. Neuroprotective Effects of Bordo Juice and Wine. We investigated whether Bordo grape juice and wine could prevent $\mathrm{H}_{2} \mathrm{O}_{2}$-induced intracellular $\mathrm{ROS}$ production in SH-SY5Y cells and promote neuroprotective actions (Figure 3). Our results showed that exposure to $\mathrm{H}_{2} \mathrm{O}_{2}$ increased the intracellular ROS production (Figures $3(\mathrm{a})$ and $3(\mathrm{~b})$ ). However, 500 and $1000 \mu \mathrm{g} / \mathrm{mL}$ of Bordo grape juice significantly $(p<0.05$ and $p<0.001)$ reduced $\mathrm{H}_{2} \mathrm{O}_{2}$-induced production of ROS (Figure 3(a)), whereas $1000 \mu \mathrm{g} / \mathrm{mL}$ of Bordo grape wine had a prooxidant effect per se by increasing the DCF levels in the absence of $\mathrm{H}_{2} \mathrm{O}_{2}(p<0.001$; Figure 3(b)). Bordo grape wine was unable to prevent the increase in ROS induced by $\mathrm{H}_{2} \mathrm{O}_{2}$ and only $1000 \mu \mathrm{g} / \mathrm{mL}$ of Bordo grape wine induced further increase in ROS levels compared with $\mathrm{H}_{2} \mathrm{O}_{2}$ (Figure $3(\mathrm{~b}), p<0.05$ ).

To determine whether Bordo grape juice and wine could protect against oxidative stress-induced cell death, the $\mathrm{SH}$ SY5Y cell line was used as an in vitro model and $\mathrm{H}_{2} \mathrm{O}_{2}$ as prooxidant insult. After $24 \mathrm{~h}$ of $\mathrm{H}_{2} \mathrm{O}_{2}$ exposure in combination with Bordo grape juice, we observed that all tested concentrations $(250-1000 \mu \mathrm{g} / \mathrm{mL})$ of grape juice protected against $\mathrm{H}_{2} \mathrm{O}_{2}$-induced cell death (Figure 3(c); $p<0.001)$. However, Bordo wine at $1000 \mu \mathrm{g} / \mathrm{mL}$ significantly $(p<0.001)$ reduced cell viability in the absence of $\mathrm{H}_{2} \mathrm{O}_{2}$ (Figure 3(d)). In the presence of $\mathrm{H}_{2} \mathrm{O}_{2}$, only $250-500 \mu \mathrm{g} / \mathrm{mL}$ of Bordo wine protected against cytotoxicity $(p<0.01$ and $p<0.05$ ), whereas $1000 \mu \mathrm{g} / \mathrm{mL}$ of Bordo grape wine induced further cytotoxicity compared with vehicle- $\mathrm{H}_{2} \mathrm{O}_{2}$ (Figure $3(\mathrm{~d}), p<0.001)$.

\section{Discussion}

Polyphenols, which have high antioxidant capacity and exhibit strong protective effect against cellular oxidative damage, are the most abundant secondary metabolites in plants and antioxidants in human diet [38]. Grapes and derivatives contain high amounts of phenolic compounds, mainly flavonoids. In fact, high levels of phenolic compounds were found in samples of Bordo grape juice and wine used in the present study, which may contribute to the high antioxidant potential of those beverages. Furthermore, many of these compounds exhibit multiple biological activities, and these functions are mainly attributed to their antioxidant and antiradical activity $[39,40]$. The main finding of our study is that the consumption of Bordo grape juice and wine yielded similar antioxidant effects by increasing total antioxidant capacity and reducing lipid oxidation, despite the higher content of phenolic compounds and in vitro antioxidant activity of Bordo wine compared with juice.

Concerning the study of antioxidant effectiveness, the use of different in vitro models has been recommended, due to the differences between the various free radical scavenging assays [41, 42]. Thus, antioxidant activity of Bordo juice and wine were assessed using the ABTS method, which measures the scavenging of the ABTS radical cation, and the FRAP method, which measures the ability to reduce the ferrictripyridyl triazine complex (Fe III-TPX) to ferrous complex (FeII-TPZ) under acidic conditions. In our study, the ABTS assay showed significantly higher values compared with FRAP values, mainly for wine. However, the reaction of FRAP method may not be complete even several hours after the initiation of the reaction, mainly because of subsequent dimerizations and polymerizations [43]. Drawbacks of this method are concerned with compounds that have low redox 


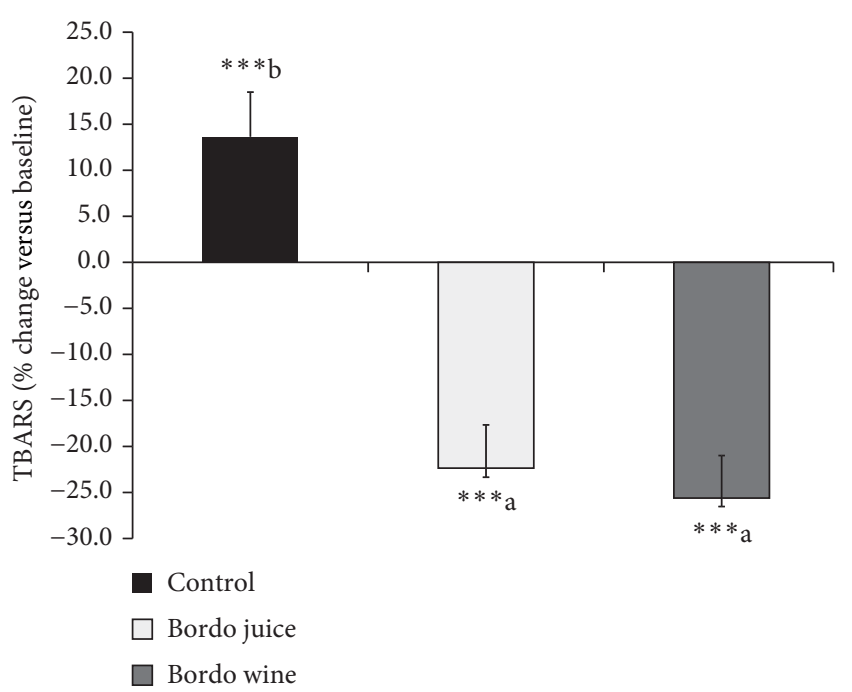

(a)

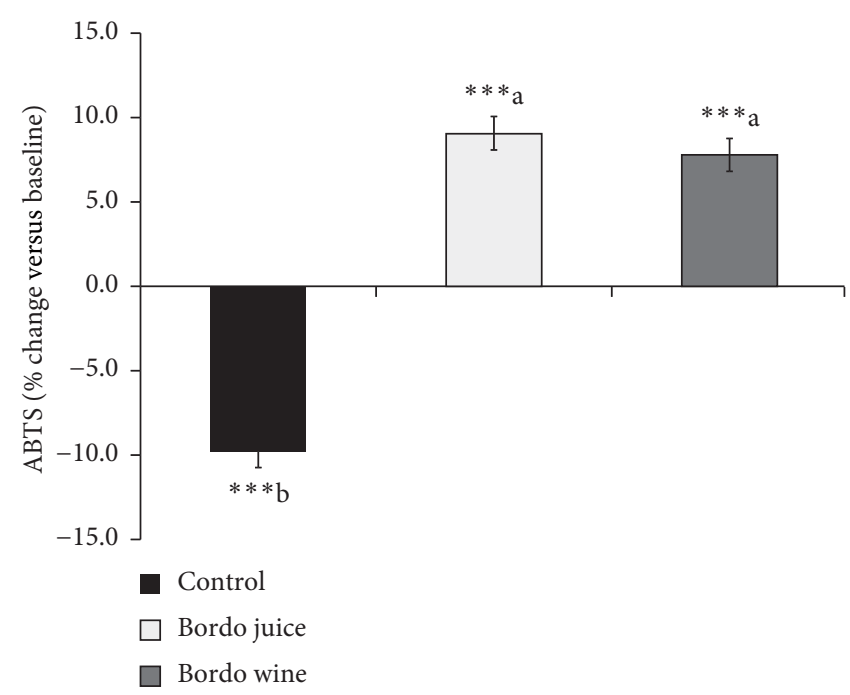

(b)

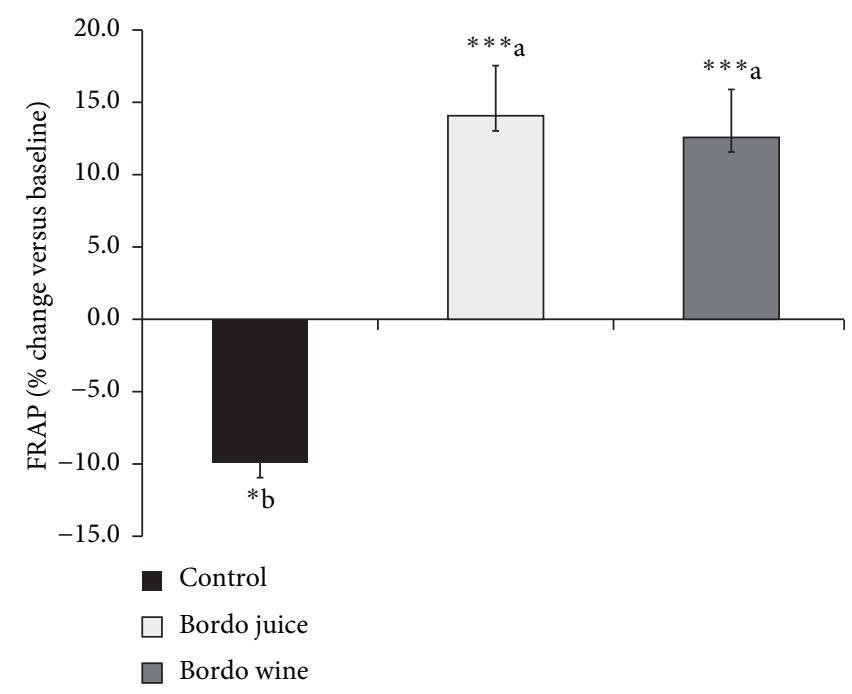

(c)

FIgURE 2: Changes in serum TBARS levels (a) and plasma antioxidant capacity assessed by the ABTS (b) and FRAP (c) assays in humans after consumption of Bordo juice, Bordo wine, or water (control). Results are expressed as percentage of baseline values for each group (means \pm SEM, $n=15$ ). ${ }^{*}$ Significantly different from baseline (paired Student's $t$-test; ${ }^{*} p<0.05,{ }^{* *} p<0.01$, and ${ }^{* * *} p<0.001$ ). ${ }^{\mathrm{a}, \mathrm{b}}$ Different letters indicate significant difference among interventions (Tukey's test, $p<0.05$ ).

potential and can reduce the Fe III even though they do not behave as antioxidants in vivo $[44,45]$, interfering compounds that can absorb at the same wavelength and the assay being performed at a nonphysiological $\mathrm{pH}$.

Numerous indices and methods have been used to assess oxidative stress, defined as an imbalance between the production of ROS and their removal by antioxidants. Among various indices, products of lipid peroxidation are the most common group used to evaluate the individual oxidative (antioxidant/prooxidant) status [5, 45]. Lipid peroxidation is a result of complex reactions which yield compounds that can be determined as TBARS [46]. According to GarcíaAlonso et al. [47] a reduction in the lipid oxidation might be associated with the intake of phenolic beverages. Our results showed a significant $(p<0.05)$ decrease in serum lipid peroxidation after the intake of both Bordo juice and wine compared with baseline values, and this effect was not observed after water intake. Similar effects were previously reported in human serum or plasma after the intake of polyphenol-rich foods, and according to these studies, the decrease in lipid peroxidation probably occurred due to the quick absorption of polyphenols into the bloodstream $[15,48,49]$. These phytochemicals are known to prevent lipid peroxidation by scavenging peroxyl radicals $[15,49,50]$. Moreover, evidence from in vitro studies indicates that resveratrol, which is among the most important grape polyphenols [51], can be accumulated into erythrocytes and activates the erythrocyte plasma membrane redox system 
TABLE 4: Glucose and uric acid levels in healthy individuals at baseline and after the interventions with Bordo grape juice, Bordo wine, and water (control).

\begin{tabular}{|c|c|c|c|}
\hline \multicolumn{4}{|c|}{ Intervention samples } \\
\hline \multirow{2}{*}{ Biochemical parameters } & \multirow{2}{*}{ Control } & \multicolumn{2}{|c|}{ Bordo grapes } \\
\hline & & Bordo juice & Bordo wine \\
\hline \multicolumn{4}{|l|}{ Serum glucose $(\mathrm{mg} / \mathrm{dL})$} \\
\hline Baseline & $84.1 \pm 5.8$ & $74.4 \pm 5.5$ & $82.2 \pm 7.1$ \\
\hline $1 \mathrm{~h}$ after intervention & $82.3 \pm 5.5$ & $69.3 \pm 6.2$ & $74.8 \pm 7.4$ \\
\hline Change versus baseline (\%) & $-2.0 \pm 1.5^{\mathrm{b}}$ & $-6.7 \pm 1.7^{\mathrm{ab} * *}$ & $-8.8 \pm 2.0^{\mathrm{a} * *}$ \\
\hline \multicolumn{4}{|l|}{ Uric acid (mg/dL) } \\
\hline Baseline & $4.8 \pm 1.9$ & $4.8 \pm 1.6$ & $4.4 \pm 1.2$ \\
\hline $1 \mathrm{~h}$ after intervention & $4.6 \pm 1.8$ & $4.6 \pm 1.5$ & $4.6 \pm 1.2$ \\
\hline Change versus baseline (\%) & $-4.6 \pm 1.4^{\mathrm{b} * *}$ & $-4.1 \pm 1.1^{\mathrm{b} * *}$ & $4.2 \pm 1.2^{\mathrm{a} *}$ \\
\hline
\end{tabular}

Results are expressed as means \pm SEM $(n=15)$. ${ }^{*}$ Significantly different from baseline (paired Student's $t$-test; ${ }^{*} p<0.05$ and $\left.{ }^{* *} p<0.01\right)$. ${ }^{\mathrm{a}, \mathrm{b}}$ Different letters indicate significant difference among interventions (Tukey's test, $p<0.05$ ).

[52]. Resveratrol may function as an electron donor for this enzymatic system, which reduces extracellular oxidants and recycles oxidized ascorbate, thereby contributing to counteract extracellular oxidative processes [52]. In addition, in silico studies revealed that other grape polyphenols, namely, quercetin, epigallocatechin gallate, catechin, and epicatechin, are able to interact and donate protons to the human NADH-cytochrome b5 reductase, which is a component of the erythrocyte plasma membrane redox system [53]. These mechanisms may underline the antioxidant effect of Bordo juice and wine in serum as observed in the present study.

Short-term studies involving the consumption of polyphenol beverages have reported acute increases in the antioxidant capacity of plasma or serum, which have usually been attributed to the high levels of polyphenolic antioxidants provided by plants $[5,18,54,55]$. Our findings showed significant $(p<0.05)$ improvement in antioxidant status after the consumption of Bordo grape juice and wine, in opposite to the ingestion of control beverage (water), therefore confirming our hypothesis that polyphenols present in the Bordo juice and wine favorably influence the antioxidant capacity in vivo. Malvidin-3-glucoside (M-3-G), which is the most abundant anthocyanin in grapes and grape products, has similar bioavailability after the ingestion of red wine or dealcoholized red wine, indicating that ethanol in red wine does not seem to affect the absolute uptake and plasma concentrations of M-3-G [56]. Furthermore, increases in plasma anthocyanin concentrations after the consumption of either red wine or dealcoholized red wine were about two times lower than those measured after consumption of red grape juice. These authors did not measure the antioxidant capacity after beverage intake. We found that anthocyanin concentration in Bordo wine was 3 times higher than in Bordo grape juice, but both beverages were similarly effective to increase blood antioxidant capacity and reduce lipid oxidation in humans after consumption.

The hypothesis that flavonoids are responsible for the increase in plasma antioxidant capacity after the intake of flavonoid-rich foods has been disputed by evidence that such an effect could be a consequence of increased uric acid levels [57]. Uric acid has been demonstrated to be one of the major contributors to the antioxidant capacity in human serum [48] and particularly contributes to the antioxidant capacity of serum assessed by the FRAP assay [18, 29]. Fructose from flavonoid-rich fruits has been demonstrated to be responsible for increasing plasma uric acid levels [57]. However, in the present study, the consumption of $100 \mathrm{~mL}$ of Bordo juice or wine did not increase glycemia. Moreover, we demonstrated that Bordo grape juice decreased blood uric acid levels, indicating that the increase in antioxidant capacity of serum was promoted by grape juice antioxidants and not by urate. Similar results were recently found after acute consumption of grape juices [18]. On the other hand, we found an increase in serum levels of uric acid after Bordo wine consumption that was parallel to the increase in plasma antioxidant capacity (FRAP and ABTS assays) and to the decrease in plasma lipid oxidation. Similar results were found for port wine consumption [58].

Assays using living cells have proven to be useful for routine testing of various products, producing reliable results for the identification of biological activities, including antioxidant capacity [59]. Excessive ROS production is associated with disruption of cell cycle regulatory mechanisms. In the present study, we used the human neuron-like cells SH-SY5Y, which were challenged with $\mathrm{H}_{2} \mathrm{O}_{2}$ that is among the major physiologically relevant ROS species $[60,61]$. Bordo juice inhibited the production of RS and the loss of cell viability induced by $\mathrm{H}_{2} \mathrm{O}_{2}$. In contrast, Bordo wine had only a small protective effect against the loss of cell viability at intermediate concentrations but increased RS production and promoted loss of cell viability per se at the highest concentration. Such an effect was not related to the ethanol content of wine as ethanol was removed by freeze-drying before the experiment.

The direct radical scavenging action of polyphenols requires the presence of the antioxidant at the exact place where such radicals are formed. Polyphenols protect biological membranes from oxidation as they interact with the lipid phase of the membrane with a tendency to incorporate into the outer hydrophilic portion of the phospholipid 


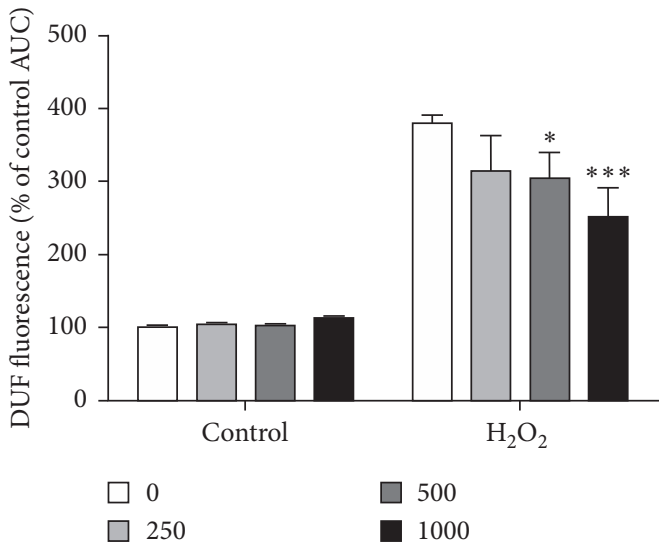

(a)

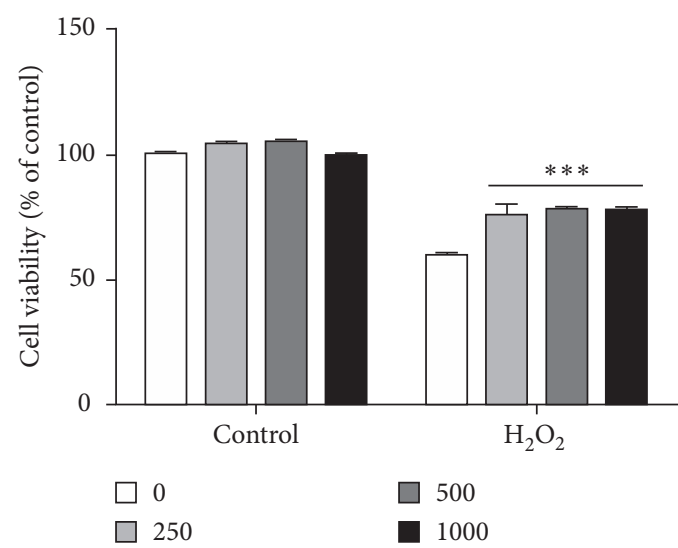

(c)

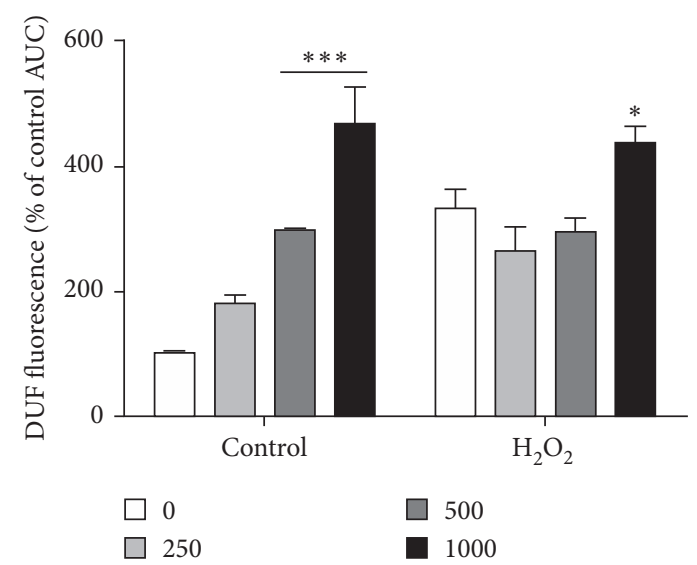

(b)

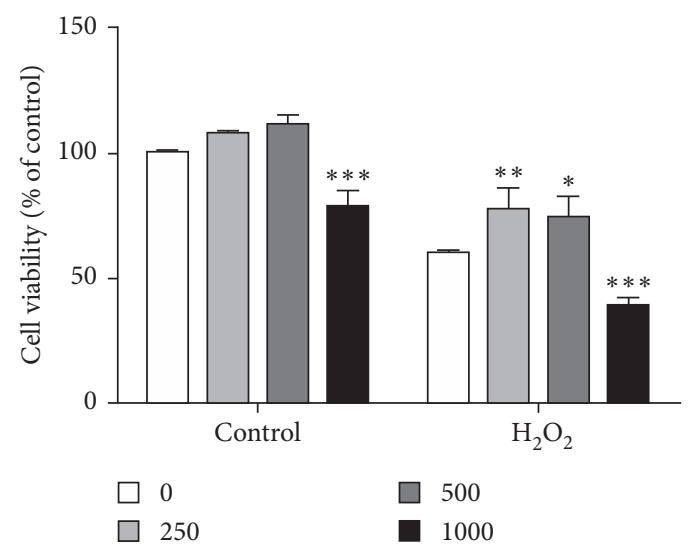

(d)

Figure 3: Effect of Bordo grape juice and wine on $\mathrm{H}_{2} \mathrm{O}_{2}$-induced cytotoxicity in SH-SY5Y cells. (a) DCF fluorescence of cells treated with Bordo grape juice. (b) DCF fluorescence of cells treated with Bordo grape wine. (c) Cell viability of cells treated with Bordo grape juice. (d) Cell viability of cells treated with Bordo grape wine. Cells were exposed to 0 (vehicle), 250, 500, and $1000 \mu \mathrm{g} / \mathrm{mL}$ of Bordo juice or Bordo wine during $5 \mathrm{~h}$ (panels (a) and (b)) or $24 \mathrm{~h}$ (panels (c) and (d)). Two-way ANOVA was applied to all data. ${ }^{*} p<0.05$, ${ }^{* *} p<0.01$, and ${ }^{* * * *} p<0.001$ versus the respective vehicle group.

bilayer [60]. The antioxidant components of fruits and vegetables, such as polyphenols, have been found to possess properties which play a role in protecting cellular macromolecules from ROS-induced damage [3, 4]. Many grape compounds could be responsible for the grape juice antioxidant activity against $\mathrm{H}_{2} \mathrm{O}_{2}$-induced damage in SH-SY5Y cells. Polyphenol composition of wines shows higher complexity when compared with their corresponding juice berries because during the winemaking and maturation processes, there are numerous reactions involving phenolic compounds (enzymatic and chemical oxidation reactions, condensation reactions, hydrolysis, etc.). We propose that wine fermentation process generates compounds that exhibit prooxidant effects at high concentrations and would be responsible for the overproduction of RS induced by the highest wine concentration $(1 \mathrm{mg} / \mathrm{mL})$ in SH-SY5Y cells. Conversely, commercial red wine from China exhibited neuroprotective effects against $\mathrm{H}_{2} \mathrm{O}_{2}$-induced oxidative stress in SH-SY5Y cells up to $4 \mathrm{mg} / \mathrm{mL}$ [62]. This discrepancy may be attributed to differences in the cultivars used to prepare the wines. Another explanation for the different effect of Bordo wine and juice in the culture assays could be the higher concentration of phenolic compounds in Bordo wine compared with Bordo juice, which could exert a prooxidant effect. In fact, Long et al. [63] showed that addition of phenolic compounds, especially epigallocatechin and epigallocatechin gallate, to the cell culture media rapidly generates substantial amounts of $\mathrm{H}_{2} \mathrm{O}_{2}$. This effect was dosedependent and significant amounts of $\mathrm{H}_{2} \mathrm{O}_{2}(200-400 \mu \mathrm{M})$ have been shown to be formed after the addition of phenolics at concentrations $\geq 100 \mu \mathrm{M}$.

The small number of individuals studied may be considered a limitation of the present study. However, it should be noted that all the analyses were paired comparisons, which has strong statistical power. In conclusion, the high amount of phenolic compounds found in samples of Bordo grape juice and wine used in the present study may contribute to the high in vitro antioxidant potential of those 
beverages. Furthermore, the in vitro antioxidant capacity can be reproduced as in vivo antioxidant after acute human intake because the consumption of Bordo grape juice and wine improved antioxidant capacity and reduced lipid oxidation in healthy volunteers. In addition, Bordo juice and wine were able to decrease glucose levels and only wine increased uric acid levels. The same way, wine did not have antioxidant effect in cell culture showing to be toxic at high concentration, whereas juice had antioxidant effects against $\mathrm{H}_{2} \mathrm{O}_{2}$-induced cellular oxidative stress. Bordo grape juice and wine can be used for improving health and as a preventive agent for oxidative stress-related diseases, but wine should be consumed in smaller doses due to the prooxidant effect observed in cell culture.

\section{Conflicts of Interest}

The authors declare no conflicts of interest.

\section{Acknowledgments}

The authors gratefully acknowledge Casa Perini Winery and the enologist Leandro Santini for providing the juice and wine samples. This work was supported by Fundação de Amparo à Pesquisa do Estado do Rio Grande do Sul (FAPERGS, Brazil).

\section{References}

[1] B. Halliwell, "Free radicals and antioxidants-quo vadis?," Trends in Pharmacological Sciences, vol. 32, no. 3, pp. 125-130, 2011.

[2] J. Lee, S. Giordano, and J. Zhang, "Autophagy, mitochondria and oxidative stress: cross-talk and redox signalling," Biochemical Journal, vol. 441, no. 2, pp. 523-540, 2012.

[3] B. Halliwell, "Reactive species and antioxidants. Redox biology is a fundamental theme of aerobic life," Plant Physiology, vol. 141, no. 2, pp. 312-322, 2006.

[4] M. Valko, D. Leibfritz, J. Moncol, M. T. D. Cronin, M. Mazur, and J. Telser, "Free radicals and antioxidants in normal physiological functions and human disease," International Journal of Biochemistry and Cell Biology, vol. 39, no. 1, pp. 44-84, 2007.

[5] N. Kardum, M. Takić, K. Šavikin et al., "Effects of polyphenolrich chokeberry juice on cellular antioxidant enzymes and membrane lipid status in healthy women," Journal of Functional Foods, vol. 9, pp. 89-97, 2014.

[6] F. L. Crowe, A. W. Roddam, T. J. Key et al., "Fruit and vegetable intake and mortality from ischaemic heart disease: results from the European Prospective Investigation into Cancer and Nutrition (EPIC)-Heart study," European Heart Journal, vol. 32, no. 10, pp. 1235-1243, 2011.

[7] J. F. D. C. Guerra, P. S. Maciel, I. C. M. E. de Abreu et al., "Dietary açaí attenuates hepatic steatosis via adiponectinmediated effects on lipid metabolism in high-fat diet mice," Journal of Functional Foods, vol. 14, pp. 192-202, 2015.

[8] M. N. Clifford, "Chlorogenic acids and other cinnamatesnature, occurrence, dietary burden, absorption and metabolism," Journal of the Science of Food and Agriculture, vol. 80, no. 7, pp. 1033-1043, 2000.
[9] K. B. Pandey and S. I. Rizvi, "Markers of oxidative stress in erythrocytes and plasma during aging in humans," Oxidative Medicine and Cellular Longevity, vol. 3, no. 1, pp. 2-12, 2010.

[10] D. Bagchi, M. Bagchi, S. J. Stohs et al., "Free radicals and grape seed proanthocyanidin extract: importance in human health and disease prevention," Toxicology, vol. 148, no. 2-3, pp. 187-197, 2000.

[11] A. Sano, R. Uchida, M. Saito et al., "Beneficial effects of grape seed extract on malondialdehyde-modified LDL," Journal of Nutritional Science and Vitaminology, vol. 53, no. 2, pp. 174-182, 2007.

[12] I. C. Arts and P. C. Hollman, "Polyphenols and disease risk in epidemiologic studies," American Journal of Clinical Nutrition, vol. 81, no. 1, pp. 317S-325S, 2005.

[13] D. Kammerer, A. Claus, R. Carle, and A. Schieber, "Polyphenol screening of pomace from red and white grape varieties (Vitis vinifera L.) by HPLC-DAD-MS/MS," Journal of Agricultural and Food Chemistry, vol. 52, no. 14, pp. 43604367, 2004.

[14] A. Y. Sun, Q. Wang, A. Simonyi, and G. Y. Sun, "Botanical phenolics and brain health," NeuroMolecular Medicine, vol. 10, no. 4, pp. 259-274, 2008.

[15] I. M. Toaldo, F. A. Cruz, T. L. Alves et al., "Bioactive potential of Vitis labrusca L. grape juices from the Southern Region of Brazil: phenolic and elemental composition and effect on lipid peroxidation in healthy subjects," Food Chemistry, vol. 173, pp. 527-535, 2015.

[16] P. Castilla, R. Echarri, A. Dávalos et al., "Concentrated red grape juice exerts antioxidant, hypolipidemic, and antiinflammatory effects in both hemodialysis patients and healthy subjects," American Journal of Clinical Nutrition, vol. 84, no. 1, pp. 252-262, 2006.

[17] C. Dani, L. S. Oliboni, R. Vanderlinde, D. Bonatto, M. Salvador, and J. A. P. Henriques, "Phenolic content and antioxidant activities of white and purple juices manufactured with organically or conventionally produced grapes," Food and Chemical Toxicology, vol. 45, no. 12, pp. 2574-2580, 2007.

[18] I. M. Toaldo, F. A. Cruz, E. L da Silva, and M. T. BordignonLuiz, "Acute consumption of organic and conventional tropical grape juices (Vitis labrusca L.) increases antioxidants in plasma and erythrocytes, but not glucose and uric acid levels, in healthy individuals," Nutrition Research, vol. 36, no. 8, pp. 808-817, 2016.

[19] C. R. Pace-Asciak, O. Rounova, S. E. Hahn, E. P. Diamandis, and D. M. Goldberg, "Wines and grape juices as modulators of platelet aggregation in healthy human subjects," Clinica Chimica Acta, vol. 246, no. 1-2, pp. 163-182, 1996.

[20] S. R. Coimbra, S. H. Lage, L. Brandizzi, V. Yoshida, and P. L. da Luz, "The action of red wine and purple grape juice on vascular reactivity is independent of plasma lipids in hypercholesterolemic patients," Brazilian Journal of Medical and Biological Research, vol. 38, no. 9, pp. 1339-1347, 2005.

[21] F. A. van Dorsten, C. H. Grun, E. J. van Velzen, D. M. Jacobs, R. Draijer, and J. P. van Duynhoven, "The metabolic fate of red wine and grape juice polyphenols in humans assessed by metabolomics," Molecular Nutrition and Food Research, vol. 54, no. 7, pp. 897-908, 2010.

[22] V. M. Burin, N. E. Ferreira-Lima, C. P. Panceri, and M. T. Bordignon-Luiz, "Bioactive compounds and antioxidant activity of Vitis vinifera and Vitis labrusca grapes: evaluation of different extraction methods," Microchemical Journal, vol. 114, pp. 155-163, 2014. 
[23] L. A. Rizzon and M. Link, "Composição do suco de uva caseiro de diferentes cultivares," Ciência Rural, vol. 36, no. 2, pp. 689-692, 2006.

[24] P. Pszczólkowski and C. C. de Lecco, Manual de Vinificación: Guía práctica para la elaboración de vinos, E. U. C. de Chile Ed., Chile: Ediciones Universidad católica de Chile, Santiago, Chile, 2011.

[25] V. L. Singleton and J. A. Rossi, "Colorimetry of total phenolics with phosphomolybdic-phosphotungstic acid reagents," American Journal of Enology and Viticulture, vol. 16, pp. 144-158, 1965.

[26] P. Ribéreau-Gayon and E. Stonestreet, "Le dosage dês antocyanes dans le vin rouge," Bulletin de la Société Chimique de France, vol. 9, pp. 2649-2652, 1965.

[27] J. Zhishen, T. Mengcheng, and W. Jianming, "The determination of flavonoid contents in mulberry and the scavenging effects on superoxide radicals," Food Chemistry, vol. 64, no. 4, pp. 555-559, 1999.

[28] R. Re, N. Pellegrini, A. Proteggemnte, A. Pannala, M. Yang, and C. Rice-Evans, "Antioxidant activity applying and improved ABTS radical cation decolorization assay," Free Radical Biology and Medicine, vol. 26, no. 9-10, pp. 1234-1237, 1999.

[29] I. F. F. Benzie and J. J. Strain, "The ferric reducing ability of plasma (FRAP) as a measure of antioxidant power: the FRAP assay," Analytical Biochemistry, vol. 239, no. 1, pp. 70-76, 1996.

[30] C. Manach, A. Scalbert, C. Morand, C. Rémésy, and L. Jiménez, "Polyphenols: food sources and bioavailability," American Journal of Clinical Nutrition, vol. 79, no. 5, pp. 727-747, 2004.

[31] H. Ohkawa, N. Ohishi, and K. Yagi, "Assay for lipid peroxides in animal tissues by thiobarbituric acid reaction," Analytical Biochemistry, vol. 95, no. 2, pp. 351-358, 1979.

[32] H. Wang and J. A. Joseph, "Quantifying cellular oxidative stress by dichlorofluorescein assay using microplate reader," Free Radical Biology and Medicine, vol. 27, no. 5-6, pp. 612616, 1999.

[33] T. K. Rabelo, F. Zeidán-Chuliá, and L. M. Vasques, "Redox characterization of usnic acid and its cytotoxic effect on human neuron-like cells (SH-SY5Y)," Toxicology in Vitro, vol. 26, no. 2, pp. 304-314, 2012.

[34] D. P. Gelain and J. C. Moreira, "Evidence of increased reactive species formation by retinol, but not retinoic acid, in PC12 cells," Toxicology in Vitro, vol. 22, no. 3, pp. 553-558, 2008.

[35] M. Ferrari, M. C. Fornasiero, and A. M. Isetta, "MTT colorimetric assay for testing macrophage cytotoxic activity in vitro," Journal of Immunological Methods, vol. 131, no. 2, pp. 165-172, 1990.

[36] M. V. B. Malachias, W. K. S. B. Souza, F. L. Plavnik et al., "7 Diretriz Brasileira de Hipertensão Arterial," Arquivos Brasileiros de Cardiologia, vol. 107, no. 3, pp. 1-83, 2016.

[37] P. A. James, S. Oparil, B. L. Carter et al., " 2014 evidence-based guideline for the management of high blood pressure in adults: report from the panel members appointed to the Eighth Joint National Committee (JNC 8)," JAMA, vol. 311, no. 5, pp. 507-520, 2014.

[38] C. Manach, A. Mazur, and A. Scalbert, "Polyphenols and prevention of cardiovascular diseases," Current Opinion in Lipidology, vol. 16, no. 1, pp. 77-84, 2005.

[39] M. Seruga, Y. Novak, and L. Jakobek, "Determination of polyphenols content and antioxidant activity of some red wines by differential pulse voltammetry, HPLC and spectrophotometric methods," Food Chemistry, vol. 124, no. 3, pp. 1208-1216, 2011.

[40] M. V. Baroni, D. P. N. Romina, C. García-Ferreyra, S. Otaiza, and D. A. Wunderlin, "How good antioxidant is the red wine? Comparison of some in vitro and in vivo methods to assess the antioxidant capacity of Argentinean red wines," LWT-Food Science and Technology, vol. 47, no. 1, pp. 1-7, 2012.

[41] G. Ruberto, A. Renda, C. Daquino et al., "Polyphenol constituents and antioxidant activity of grape pomace extracts from five Sicilian red grape cultivars," Food Chemistry, vol. 100, no. 1, pp. 203-210, 2007.

[42] I. I. Rockenbach, E. Rodrigues, L. V. Gonzaga et al., "Phenolic compounds content and antioxidant activity in pomace from selected red grapes (Vitis vinifera L. and Vitis labrusca L.) widely produced in Brazil," Food Chemistry, vol. 127, no. 1, pp. 174-179, 2011.

[43] N. Nenadis, O. Lazaridou, and M. Z. Tsimidou, "Use of reference compounds in antioxidant activity assessment," Journal of Agricultural and Food Chemistry, vol. 55, no. 14, pp. 5452-5460, 2007.

[44] J. Pérez-Jiménez, J. Serrano, M. Tabernero et al., "Effects of grape antioxidant dietary fiber in cardiovascular disease risk factors," Nutrition, vol. 24, no. 7-8, pp. 646-653, 2008.

[45] Y. Dotan, D. Lichtenberg, and I. Pinchuk, "Lipid peroxidation cannot be used as a universal criterion of oxidative stress," Progress in Lipid Research, vol. 43, no. 3, pp. 200-227, 2004.

[46] K. Moore and L. J. Roberts, "Measurement of lipid peroxidation," Free Radical Research, vol. 28, no. 6, pp. 659-671, 1998.

[47] J. García-Alonso, G. Rosa, L. Vidal-Guevara, and M. J. Periago, "Acute intake of phenolic-rich juice improves antioxidant status in healthy subjects," Nutrition Research, vol. 26, no. 7, pp. 330-339, 2006.

[48] G. K. Vieira, P. F. Di Pietro, E. L. da Silva, G. S. C. Borges, E. C. Nunes, and R. Fett, "Improvement of serum antioxidant status in humans after the acute intake of apple juices," Nutrition Research, vol. 32, no. 3, pp. 229-232, 2012.

[49] A. L. Cardoso, P. F. Di Pietro, F. G. K. Vieira et al., "Acute consumption of juçara juice (Euterpe edulis) and antioxidant activity in healthy individuals," Journal of Functional Foods, vol. 17, pp. 152-162, 2015.

[50] E. F. Gris, F. Mattivi, E. A. Ferreira et al., "Phenolic profile and effect of regular consumption of Brazilian red wines on in vivo antioxidant activity," Journal of Food Composition and Analysis, vol. 31, no. 1, pp. 31-40, 2013.

[51] K. B. Pandey and S. I. Rizvi, "Plant polyphenols as dietary antioxidants in human health and disease," Oxidative Medicine and Cellular Longevity, vol. 2, no. 5, pp. 270-278, 2009.

[52] S. I. Rizvi and K. B. Pandey, "Activation of the erythrocyte plasma membrane redox system by resveratrol: a possible mechanism for antioxidant properties," Pharmacological Reports, vol. 62, no. 4, pp. 726-732, 2010.

[53] R. K. Kesharwani, D. V. Singh, K. Misra, and S. I. Rizvi, "Plant polyphenols as electron donors for erythrocyte plasma membrane redox system: validation through in silico approach," Organic and Medicinal Chemistry Letters, vol. 2, no. 1, p. 12, 2012.

[54] B. C. B. Boaventura, P. F. Di Pietro, G. A. Klein et al., "Antioxidant potential of mate tea (Ilex paraguariensis) in type 2 diabetic mellitus and pre-diabetic individuals," Journal of Functional Foods, vol. 5, no. 3, pp. 1057-1064, 2013.

[55] D. J. O'Byrne, S. Devaraj, S. M. Grundy, and I. Jialal, "Comparison of the antioxidant effects of Concord grape juice flavonoid and a-tocopherol on markers of oxidative stress in 
healthy adults," American Journal of Clinical Nutrition, vol. 76, no. 6, pp. 1367-1374, 2002.

[56] A. Bub, B. Watzl, D. Heeb, G. Rechkemmer, and K. Briviba, "Malvidin-3-glucoside bioavailability in humans after ingestion of red wine, dealcoholized red wine and red grape juice," European Journal of Nutrition, vol. 40, no. 3, pp. 113-120, 2001.

[57] S. B. Lotito and B. Frei, "Consumption of flavonoid-rich foods and increases plasma antioxidant capacity in humans: cause, consequence, or epiphenomenon?," Free Radical Biology and Medicine, vol. 41, no. 12, pp. 1727-1746, 2006.

[58] A. Day and D. Stansbie, "Cardioprotective effect of red wine may be mediated by urate," Clinical Chemistry, vol. 41, no. 9, pp. 1319-1320, 1995.

[59] S. Cyboran, J. Oszmiański, and H. Kleszczyńska, "Interaction between plant polyphenols and the erythrocyte membrane," Cellular and Molecular Biology Letters, vol. 17, no. 1, pp. 77-88, 2012.

[60] E. Birben, U. M. Sahiner, C. Sackesen, S. Erzurum, and O. Kalayci, "Oxidative stress and antioxidant defense," World Allergy Organization Journal, vol. 5, no. 1, pp. 9-19, 2012.

[61] M. Anastasiadi, H. Pratsinis, D. Kletsas, A. L. Skaltsounis, and S. A. Haroutounian, "Bioactive non-coloured polyphenols content of grapes, wines and vinification by-products: evaluation of the antioxidant activities of their extracts," Food Research International, vol. 43, no. 3, pp. 805-813, 2010.

[62] L. Xiang, L. Xiao, Y. Wang, H. Li, Z. Huang, and X. He, "Health benefits of wine: don't expect resveratrol too much," Food Chemistry, vol. 156, pp. 258-263, 2014.

[63] L. H. Long, M. V. Clement, and B. Halliwell, "Artifacts in cell culture: rapid generation of hydrogen peroxide on addition of $(-)$-epigallocatechin, $(-)$-epigallocatechin gallate, $(+)$-catechin, and quercetin to commonly used cell culture media," Biochemical and Biophysical Research Communications, vol. 273, no. 1 , pp. $50-53,2000$. 


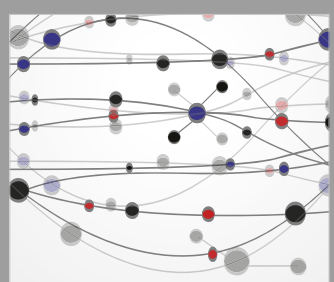

The Scientific World Journal
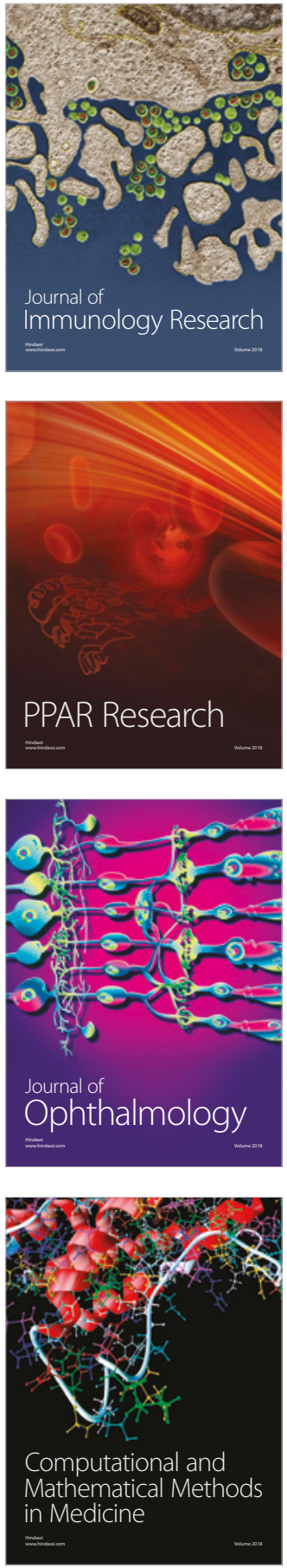

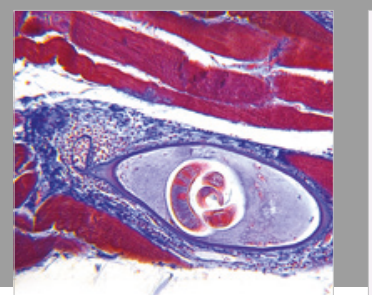

Gastroenterology Research and Practice

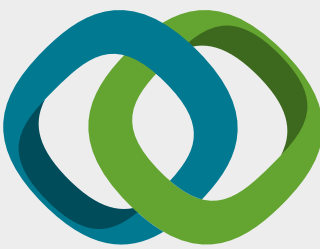

\section{Hindawi}

Submit your manuscripts at

www.hindawi.com
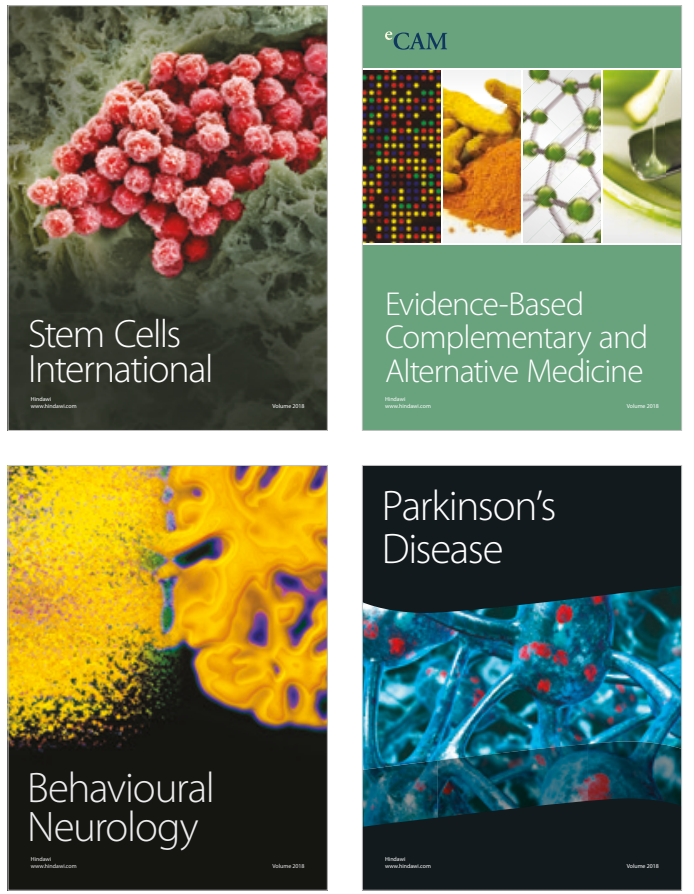

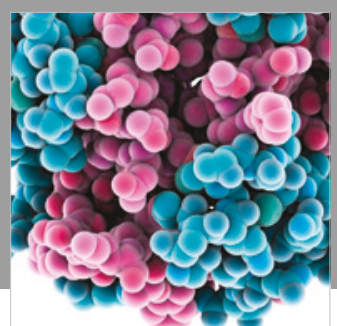

ournal of

Diabetes Research

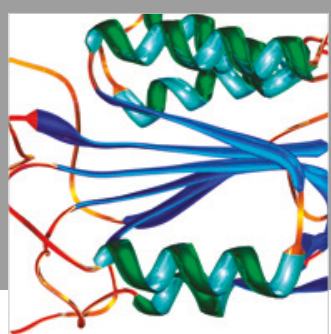

Disease Markers
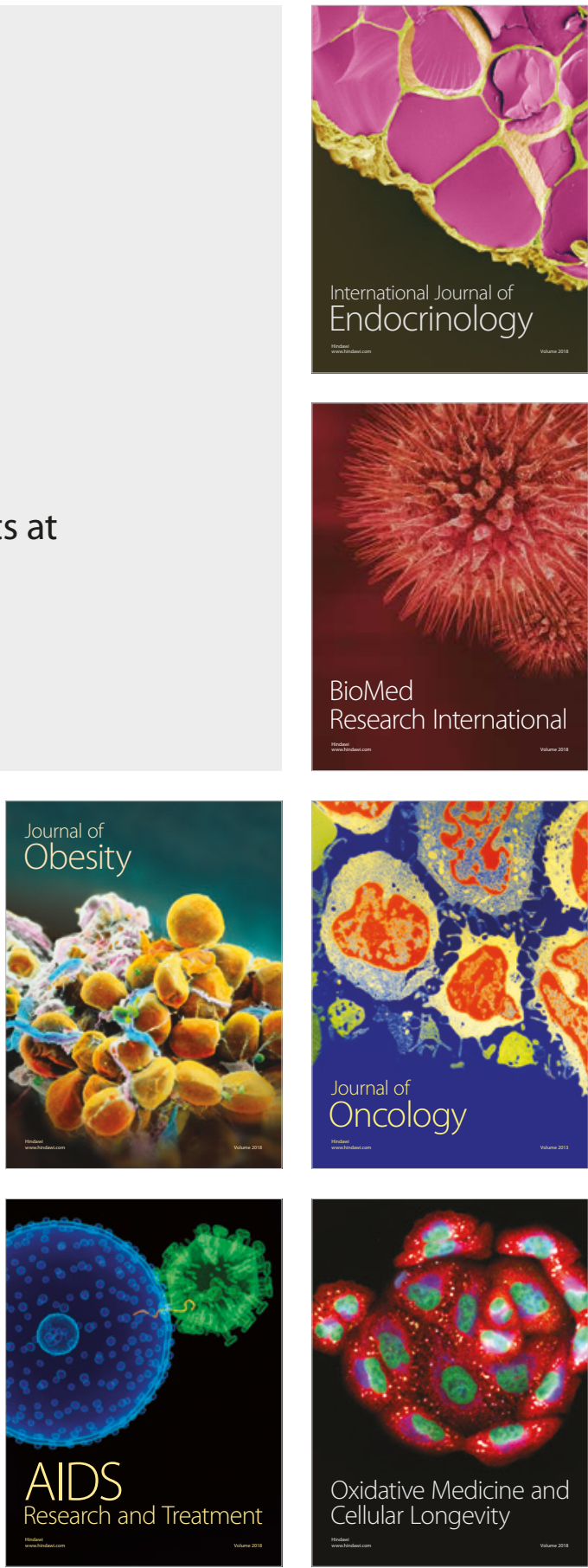